\title{
ENSINO DE TRIGONOMETRIA NUMA ABORDAGEM HISTÓRICA - UM PRODUTO EDUCACIONAL
}

\author{
S. C. GOMES
Instituto Federal do Rio Grande do Norte
severino.gomes@ifrn.edu.br \\ Artigo submetido em setembro/2011 e aceito em junho/2015 \\ DOI: $10.15628 /$ holos.2015.683
}

\section{RESUMO}

Esse trabalho objetiva relatar a construção de um caderno de atividades para o ensino de trigonometria enfocando a fusão possível entre a abordagem histórica e o ensino de matemática. Para isso são feitas considerações sobre a história da matemática enquanto metodologia de ensino, sobre a formação do professor de matemática que vai ensinar trigonometria e sobre curso de extensão realizado com participação de professores de matemática do ensino básico. Por fim apresentam-se argumentos utilizados no curso sobre a sequência de ensino e a tênue relação entre história da matemática e conteúdo matemático escolar.

PALAVRAS-CHAVE: Trigonometria, Ensino, História da Matemática, Geometria.

\section{TEACHING OF TRIGONOMETRY IN A HISTORICAL APPROACH - AN EDUCATIONAL PRODUCT}

\begin{abstract}
This paper aims to report the construction of detailed activities for teaching trigonometry focusing on the possible merger between the historical approach and the teaching of mathematics. For this we discuss the history of mathematics as a teaching methodology on the training of mathematics teachers who will teach the
\end{abstract}

course on trigonometry and extension carried out with participation of teachers in basic education. Finally, we present arguments used in the course of the sequence of teaching and tenuous relationship between history of mathematics and school mathematics content.

KEYWORDS: Trigonometry, Teaching, History of Mathematics, Geometry. 


\section{INTRODUÇÃO}

Nas últimas décadas, a consolidação da Educação Matemática como campo científico trouxe à tona inúmeras discussões sobre o ensino e a aprendizagem da Matemática. Algumas dessas discussões nos levam a refletir, por um lado, sobre os entraves de muitos alunos com a aprendizagem em Matemática e, por outro, na formação do professor, pois os conteúdos matemáticos devem ser bem compreendidos para que possam ser bem ensinados.

Uma das alternativas consideradas atualmente é o ensino de Matemática através da abordagem histórica. São muitos os pesquisadores em Educação Matemática que apóiam a História da Matemática como fonte importante na formação do estudante, em qualquer nível de ensino.

Sobre essa importância, Ferreira (2001, p. 15) argumenta que a História da Matemática "dá ao aluno a noção exata desta ciência, como uma ciência em construção, com erros e acertos e sem verdades universais". Ou seja, através da História o estudante/professor passa a conhecer a Matemática como um saber que tem significado dentro de um contexto e que foi, e está sendo, construído pela necessidade de cada época.

Porém, mesmo admitindo que a História da Matemática traz benefícios para o ensino, duas questões são motivo de discussões entre os educadores matemáticos. A primeira delas diz respeito a como está sendo a preparação dos professores de Matemática para a utilização dessa abordagem; e a segunda se refere às estratégias de ensino pertinentes e como devem ser aplicadas.

Pensando nisso, na formação e na qualificação de profissionais de ensino, principalmente, na área de Ciências Naturais e Matemática, surgiram no Brasil, na década passada, os cursos de mestrado profissional em ensino. Com proposta diferente dos cursos de mestrado acadêmico ${ }^{1}$, o mestrado profissional em ensino

[...] deverá ter caráter de preparação profissional na área docente, focalizando o ensino, a aprendizagem, o currículo, a avaliação e o sistema escolar. Deverá, também, estar sempre voltado explicitamente para a evolução do sistema de ensino, seja pela ação direta em sala de aula, seja pela contribuição na solução de problemas dos sistemas educativos, nos níveis fundamental e médio. (OSTERMANN; REZENDE, 2009, p. 69).

Ou seja, os cursos de mestrado profissional em ensino devem ter foco no desenvolvimento de produtos de natureza educacional. O material produzido nestes cursos não deve visar somente à melhoria do ensino de determinados conteúdos, mas, propor reflexões sobre problemas educacionais ${ }^{2}$ enfrentados pelo professor. Além disso, deve-se considerar a qualidade do material produzido e sua divulgação não somente nos espaços acadêmicos. Isso é fundamental para que ele seja amplamente utilizado por outros profissionais da área específica.

\footnotetext{
${ }^{1}$ Os cursos de mestrado acadêmico têm foco na formação de pesquisadores a longo prazo enquanto os cursos de mestrado profissional qualificam para o mercado de trabalho. (OSTERMANN; REZENDE, 2009).

2 Entendemos como problemas educacionais assuntos referentes à formação continuada do professor, escolha adequada de estratégias de ensino, reflexões sobre o currículo e sobre o livro didático.
} 
A opção pela trigonometria como objeto de estudo se deu por percebemos, no decorrer desse período como professor, que nossos alunos apresentam dificuldades em interpretar enunciados de problemas, em aplicar conceitos básicos de geometria e trigonometria e em trabalhar com determinadas técnicas algébricas essenciais à formação de alguns conceitos trigonométricos.

Esses fatos nos remetem a uma preocupação constante enquanto educador matemático: o ensino e a aprendizagem de trigonometria não são os desejados. Brito e Morey $(2004$, p. 11) apontam a gravidade do problema em estudo realizado com cinquenta professores da rede de ensino de nosso Estado. Elas afirmam que os professores, "na maior parte das vezes, tiveram em seus cursos de graduação pouca ênfase no ensino de geometria e praticamente nenhuma no de trigonometria."

Ainda nesse contexto, a temática se faz pertinente por apresentar inquietação não somente desse educador: "o que vem ocorrendo com o ensino de trigonometria que não resulta em aprendizagem, por parte dos alunos?" (NACARATO; BREDARIOL; PASSOS, 2007, p. 65).

A resposta para essa pergunta está ligada a diversos aspectos relativos à formação dos professores, às metodologias de ensino empregadas, como citadas anteriormente, ao livro didático como fonte de planejamento e à grade curricular de Matemática.

Para atender essas demandas, diversos fatores devem ser considerados ao se implementar uma sequência de atividades que una a História aos conteúdos matemáticos de forma indissolúvel. Dentre eles estão a minúscula disponibilidade de literatura específica e, principalmente, a carência na nossa formação como professores.

Por fim, escolhemos a História da Matemática como abordagem de ensino por acreditar que um curso para professores de Matemática (em exercício e em formação) deve conter algo mais que somente conteúdos matemáticos. Esses cursos devem estabelecer, sobretudo, uma relação entre teoria e prática, de forma a esclarecer melhor as inter-relações do que se aprende na formação e na escola, na qual o professor necessita assumir suas próprias ações.

\section{A HISTÓRIA DA MATEMÁtICA E O ENSINO DE MATEMÁtICA: ALGUMAS CONSIDERAÇÕES}

Nas últimas décadas, houve um interesse crescente no papel que a História da Matemática pode desempenhar na melhoria do ensino e da aprendizagem da Matemática. Diversos estudiosos, em vários países, argumentam sobre o papel da História da Matemática, em suas várias dimensões, em todos os níveis do sistema educacional, em suas relações com o ensino e a aprendizagem, bem como no que diz respeito à formação do professor de Matemática. A divulgação desses estudos vem impulsionando os educadores matemáticos a refletir sobre as potencialidades e as limitações do uso da História da Matemática no ensino.

Apesar de não ser consenso entre os educadores matemáticos, o estudo sobre a utilização da História da Matemática com fins pedagógicos vem se ampliando. Baroni e Nobre (1999, p. 135) afirmam que esse estudo "ainda não possui fundamentações sólidas que possam se constituir em parâmetros claros de atuação." 
Porém, argumentos apresentados por Mendes (2001a), Baroni, Teixeira e Nobre (2004) e Miguel e Miorim (2005) preconizam que a utilização da História da Matemática no ensino contribui na contextualização dos conteúdos matemáticos, na desmistificação da Matemática e na compreensão do processo dinâmico da construção do conhecimento matemático ao longo dos tempos.

Para esses pesquisadores quando a História da Matemática apresenta as características citadas, ela é uma grande aliada no ensino e aprendizagem, pois

Em diversas situações, tendo a matemática como um recurso, pode se esclarecer ideias matemáticas que estão sendo construídas por estudantes, especialmente para dar respostas a algumas perguntas e, desta forma, contribuir para a constituição de um olhar crítico sobre os objetos do conhecimento. (FASANELLI, 2002, p. 4, tradução nossa).

Nessa perspectiva, a História da Matemática pode transformar (ou não) uma situação de ensino tradicional ${ }^{3}$, independente do nível de ensino, em um processo exploratório contextualizado. Nesse processo, professor e estudante participam ativamente analisando e discutindo a formação do conhecimento no passado, atrelados ao desenvolvimento intelectual no presente.

Embasados nos pressupostos citados, assim como em Fasanelli (2002), acreditamos que a forma como a História da Matemática pode ser usada em sala de aula deve variar de acordo com o nível de ensino, pois os estudantes, nas diversas faixas etárias, têm necessidades e possibilidades diferentes.

A esse respeito, podemos ressaltar que na formação ou no aperfeiçoamento de professores de Matemática, a História pode contribuir no desenvolvimento de hábitos de leitura tão negligenciados nos nossos cursos de formação. Já no ensino básico, a investigação da evolução matemática dentro de contextos sócio-culturais pode conduzir à constatação de que todas as culturas humanas têm dado origem a desenvolvimentos matemáticos que estão agora à disposição de todos.

Porém, como mencionado anteriormente, a utilização da História da Matemática com fins pedagógicos não é consenso entre educadores matemáticos. Baroni e Nobre $(1999$, p. 130) argumentam que se deve ter cautela em propor a utilização da História da Matemática em sala de aula. Para eles, a História da Matemática "é uma área do conhecimento matemático, um campo de investigação científica, por isso é ingênuo considerá-la como um simples instrumento metodológico".

Neste aspecto, antes de propor a utilização da História da Matemática com fins pedagógicos, devemos considerar que

A história pode se tornar um dificultador para a compreensão dos conceitos; uma visão distorcida do passado pode impossibilitar uma contextualização eficaz da matemática; a aversão que algum aluno possa ter à História implicaria uma aversão à História da Matemática e, consequentemente, à Matemática; o estudo

\footnotetext{
${ }^{3} \mathrm{Na}$ perspectiva da condução da aula pelo professor na qual ele é o detentor do saber e os alunos, meros expectadores reproduzindo técnicas mostradas para resolver exercícios similares aos apresentados.
} 
do passado é perda de tempo, dado que os avanços da Matemática ocorrem exatamente para resolver problemas complicados; outros fatores de ordem prática tais como: falta de tempo para cumprir o programa; falta de recursos materiais; falta de experiência do professor; dificuldade de avaliação. (BARONI; TEIXEIRA; NOBRE, 2004, p. 167-168).

Ou seja, a reflexão sobre a inserção da História da Matemática nos campos do ensino e da aprendizagem dos conteúdos matemáticos somente vem estreitar e fortalecer suas relações com a Educação Matemática, abrindo diversas possibilidades de estudos e pesquisas nessa temática.

Para aqueles que defendem a História da Matemática como motivadora de aprendizagem, há de se considerar que não basta pensarmos nela como uma simples motivadora nas aulas. "Sua amplitude extrapola o campo da motivação e engloba elementos cujas naturezas estão voltadas a uma interligação entre o conteúdo e sua atividade educacional." (BARONI; NOBRE, 1999, p. 132).

Em nosso entendimento, o domínio da história do conteúdo que o professor de Matemática trabalha em sala de aula é fundamental para fortalecer essa interligação.

No entanto, a maioria dos professores das escolas necessita de apoio para introduzir em sua sala de aula uma nova abordagem. Este é o caso da introdução da História da Matemática no processo de ensino, como podemos ler no artigo de autoria de Siu (2004/2007).

Neste artigo Siu mostra que, de acordo com dados obtidos num estudo com 360 professores de 41 escolas, os professores consideram importante o uso da História da Matemática na sala de aula, porém, estes mesmos professores declaram que eles não lançam mão deste recurso. Siu, neste mesmo artigo, nos fornece dados obtidos de 608 respondentes, todos eles professores de matemática em formação ou em formação continuada que apontam pelo menos 15 razões para eles não usarem a História da Matemática em suas aulas. Algumas destas razões apontadas gozam de mais unanimidade e, já outras, de menos. Aqui iremos focalizar apenas duas delas:

1. Falta de material adequado (citado por $64.47 \%$ dos respondentes).

2. Falta de formação adequada (citado por $82.89 \%$ dos respondentes).

Apoiados por resultados apresentados em publicações como a mencionada acima e em nossa experiência de anos trabalhando com o ensino de trigonometria foi que decidimos buscar meios de amenizar as lacunas a que se refere os pontos 1 e 2 citados.

Independente dessas discussões, acreditamos que o conhecimento de um pouco da História da Matemática é indispensável na formação de qualquer educador matemático em qualquer nível de ensino. Somente assim nós, e nossos alunos, poderíamos caminhar rumo uma visão da Matemática pautada em dois aspectos fundamentais: por um lado, um sistema coerente e, por outro, uma criação da humanidade, cujas ideias estão sempre mudando e sendo redefinidas.

\section{O PROFESSOR DE MATEMÁTICA QUE PRECISA ENSINAR TRIGONOMETRIA}

Em breve histórico sobre os cursos de licenciatura no Brasil, Moreira e David (2007) relatam que, no início, eles se constituíam de três anos voltados à formação específica e apenas 
um ano para a formação pedagógica. Ou seja,

O saber considerado relevante para a formação profissional do professor era, fundamentalmente, o conhecimento disciplinar específico. O que hoje é denominado formação pedagógica se reduzia à didática e esta, por sua vez, a um conjunto de técnicas úteis para a transmissão do saber adquirido nos três anos iniciais. (MOREIRA; DAVID, 2007, p. 13).

Somente a partir da década de 1970, os cursos de licenciatura começaram a ter mudanças estruturais. Dentro destas mudanças, iniciaram-se discussões sobre o processo de formação do professor no qual o conhecimento específico de cada área não deveria ser foco principal. Daí veio a necessidade de visualizar o professor não somente como um ministrante de conteúdos, um repassador de informações, mas sim, como um educador preocupado com os procedimentos do ensino e da aprendizagem.

A discussão entre a formação do professor e a prática docente ganhou destaque em diversos estudos publicados a partir da década de 1990. Em um destes estudos, enfocando particularmente a Matemática, Fiorentini e Lorenzato (2007) explicam que se deve diferenciar o matemático do educador matemático, pois o matemático prioriza os conteúdos matemáticos e a formação de pesquisadores em Matemática. Já o educador matemático deve conceber a Matemática como um instrumento de formação educacional ampla. Ou seja, a Matemática deve estar a serviço da educação e não somente da própria Matemática.

Como professor de Matemática em exercício há mais de quinze anos, vivenciamos uma formação escolar e acadêmica com métodos, técnicas e práticas voltadas para a Matemática em si ocupando a maioria do nosso processo formativo. São anos de domínio da pedagogia tecnicista, onde a aprendizagem resulta de uma forma de ensino que enfatiza cálculos e técnicas em prejuízo dos significados.

Com relação à formação do professor de Matemática que vai trabalhar com o ensino de trigonometria, vamos considerar alguns aspectos. Em primeiro lugar, a trigonometria faz parte do campo matemático. Portanto, o ensino de trigonometria está interligado ao ensino da própria Matemática e suas peculiaridades.

Um segundo aspecto é relativo à formação escolar, acadêmica e em exercício desse professor. A aparente insegurança do professor que vai ensinar trigonometria, independentemente do tipo de abordagem ${ }^{4}$, além das lacunas na sua formação, pode estar ligada ao tratamento trigonométrico utilizado nos livros didáticos. Sobre esse tratamento, Lima (2001, p. 47) afirma que é

[...] demasiadamente longo, com ênfase em trivialidades, omissões importantes, conceitos mal definidos e ausência de problemas conceituais atraente. $O$ radiano é mal definido, as calculadoras não são enfatizadas e nunca é claramente exposta a diferença entre seno (por exemplo) de um ângulo e de um número.

\footnotetext{
${ }^{4}$ Em estudo sobre o ensino de trigonometria no Brasil, Nacarato, Bredariol e Passos (2007) identificaram que os livros didáticos brasileiros enfocaram (ou ainda enfocam) a trigonometria segundo três formas de apresentação: a geometria, os vetores ou as funções circulares.
} 
Ou seja, geralmente, os livros didáticos apresentam excesso de conteúdos trigonométricos com uma imensidão de expressões matemáticas. Esse excessivo tratamento pode estar comprometendo a compreensão conceitual e o aprendizado significativo do assunto por parte de alunos e professores.

Em relação ao aspecto da formação do professor de Matemática que deve ensinar trigonometria, inúmeras são as dificuldades conceituais vivenciadas por estes professores. Brito e Morey (2004, p. 31) apontam que

[...] tais dificuldades estão intimamente relacionadas à formação escolar das décadas de 70 e 80 caracterizada, entre outros aspectos, pelo descaso para com a geometria e a trigonometria, pela formalização precoce de conceitos geométricos e trigonométricos - quando esses eram estudados -, e pela memorização de procedimentos sem a compreensão deles.

Apesar dos diversos estudos sobre essa temática, concordamos com os que defendem que a superação dessas dificuldades somente se dará com um maior empenho dos professores na sua contínua formação e na sua prática docente. Momentos de estudos, reflexões, troca de opiniões e discussões com outros professores ou com seus alunos são importantes enriquecedores na prática pedagógica de qualquer educador.

Entretanto devemos considerar a opinião de Polettini (1999, p.225). O autor afirma, com base em vários estudos, que o professor de Matemática parece ser fortemente influenciado por suas experiências enquanto estudante. Portanto, a mudança de postura do professor com relação ao ensino dos conteúdos matemáticos não se daria num curto espaço de tempo. A formação de um professor de Matemática deve ser entendida como uma formação que dura toda a vida, não somente nos momentos escolares ou acadêmicos.

Com o objetivo de apoiar professores nessa tarefa de constante aprendizado é que idealizamos o curso de extensão que agora faremos uma breve explanação.

\section{O CURSO DE EXTENSÃO: TÓPICOS DE TRIGONOMETRIA PARA O ENSINO}

Na nossa concepção, um exercício, a leitura de um texto, a explanação sobre algum assunto, um debate, são exemplos de formas diferenciadas de atividades de ensino. Com relação às sequências de atividades acreditamos que "são um conjunto de atividades ordenadas, estruturadas e articuladas para a realização de certos objetivos educacionais, que têm um princípio e um fim conhecidos tanto pelos professores como pelos alunos." (ZABALA, 1998, p. 18).

Com esse pensamento, idealizamos um curso de extensão para professores de Matemática, em exercício ou em formação, com a finalidade de apresentarmos uma sequência de atividades de ensino de trigonometria numa abordagem histórica. Este curso foi realizado no Instituto Federal de Educação, Ciência e Tecnologia do Rio Grande do Norte (IFRN) no campus Natal-Zona Norte, nos meses de outubro e novembro de 2010 com total de quarenta horas.

A primeira parte dele foi utilizada para estudos básicos de geometria através das construções geométricas com régua e compasso. Aproveitamos para apresentar o software 
GeoGebra $^{5}$ como ferramenta auxiliar ao estudo da geometria e da trigonometria. A segunda parte foi dedicada à aplicação, discussão e considerações sobre o caderno de atividades para o ensino de trigonometria, nossa proposta de ensino.

Participaram deste curso quinze professores, sendo cinco deles ainda em formação em licenciatura em Matemática e um em licenciatura em Física. Dos nove professores restantes, seis são licenciados em Matemática e três são pedagogos que exercem a função de professor de Matemática no ensino básico. Praticamente todos exercem sua função com professores em cidades no entorno de Natal.

Sobre a metodologia utilizada no curso, optamos por ministrá-los na forma de oficina pedagógica, isto é, o conteúdo do curso se desenvolve à medida que os participantes realizam, em grupos, atividades previamente elaboradas pelo professor (ministrante do curso). 0 ministrante do curso coordena as atividades dos grupos, tira dúvidas, dá sugestões, chama a atenção para aspectos que merecem reflexão, observa as dificuldades dos participantes, dentre outros aspectos.

Entendemos que, para um envolvimento efetivo entre conteúdos trigonométricos e sua história, a percepção textual e a compreensão do leitor/professor na sequência de atividades deve estar estreitamente ligada a diversos fatores. Estes fatores passam pela qualidade e clareza das informações contidas nos textos, pelo caráter variado dos recursos utilizados (tabelas, gráficos, desenhos e mapas) e pela própria estrutura de exposição das atividades com questões que mobilizem o pensamento e novas ideias.

Nessa perspectiva, utilizamos um caderno de atividades aliando conteúdos trigonométricos a sua história através de textos, desenhos, mapas, construções geométricas, tabelas, uso de máquinas de calcular e sugestões de leitura para aprofundamento das informações.

Ainda, o caderno de atividades de nosso estudo se apresenta com o intuito de que professores de Matemática possam conhecer articulações pedagógicas possíveis entre a trigonometria e sua história. E também que

A utilização da História da Matemática em sala de aula também pode ser vista
como um elemento importante no processo de atribuição de significados aos
conceitos matemáticos. É importante, porém, que esse recurso não fique
limitado à descrição de fatos ocorridos no passado ou à apresentação de
biografias de matemáticos famosos. [...] A História da Matemática pode
contribuir também para que o próprio professor compreenda algumas
dificuldades dos alunos, que, de certa maneira, podem refletir históricas
dificuldades presentes também na construção do conhecimento matemático.
(BRASIL, 2006, p.86)

Para a escolha dos conteúdos trigonométricos abordados nas atividades, além dos aspectos apresentados por Mendes (2001b), Brito e Morey (2004), Nascimento (2005) e Sampaio (2008), levamos em consideração as seguintes orientações:

\footnotetext{
${ }^{5}$ Uma ferramenta computacional gratuita para estudo da geometria e trigonometria. Está inserido nas novas tecnologias informatizadas como um software livre de geometria dinâmica.
} 
Alguns tópicos usualmente presentes no estudo da trigonometria podem ser dispensados, como, por exemplo, as outras três razões trigonométricas, as fórmulas para sen $(a+b)$ e cos $(a+b)$, que tanto exigem dos alunos para serem memorizadas. É preciso atenção à transição do seno e do co-seno no triângulo retângulo (em que a medida do ângulo é dada em graus), para o seno e o coseno, definidos como as coordenadas de um ponto que percorre um arco do círculo de raio unitário com medida em radianos. Os alunos devem ter a oportunidade de traçar gráficos referentes às funções trigonométricas, aqui se entendendo que, quando se escreve $f(x)=\operatorname{sen}(x)$, usualmente a variável $x$ corresponde à medida de arco de círculo tomada em radianos. $\mathrm{O}$ estudo das demais funções trigonométricas pode e deve ser colocado em segundo plano. (BRASIL, 2006, p. 74).

Portanto, o conteúdo trigonométrico apresentado em nosso estudo prioriza o enfoque geométrico. Com isso, além de seguir o percurso histórico, tratamos a geometria como fundamental para estudos trigonométricos. Os procedimentos algébricos enfadonhos explorados em diversos livros didáticos de trigonometria não são abordados. Em seu lugar apresentamos questões em que a investigação e o raciocínio são ferramentas fundamentais.

Levando em consideração os aspectos aqui citados, apresentamos na tabela 1 uma síntese das atividades com seus objetivos e assuntos abordados.

Tabela 1 - Quadro resumo das atividades.

\begin{tabular}{|c|c|c|c|}
\hline Atividade & Título & Objetivos & Assuntos abordados \\
\hline $1 \underline{a}$ & $\begin{array}{l}\text { Explorando polígonos } \\
\text { regulares inscritos na } \\
\text { circunferência }\end{array}$ & $\begin{array}{l}\text { Relembrar conceitos, elementos e } \\
\text { propriedades dos polígonos regulares } \\
\text { inscritos em uma circunferência. }\end{array}$ & $\begin{array}{l}\text { Circunferência e polígonos } \\
\text { regulares. }\end{array}$ \\
\hline $2 \underline{a}$ & $\begin{array}{l}\text { Calculando os } \\
\text { comprimentos de } \\
\text { algumas cordas }\end{array}$ & $\begin{array}{l}\text { Investigar relação entre as medidas do } \\
\text { ângulo central e do lado de polígonos } \\
\text { inscritos em uma circunferência. } \\
\text { Ainda, determinar o comprimento de } \\
\text { algumas cordas. }\end{array}$ & $\begin{array}{l}\text { Circunferência, polígonos } \\
\text { regulares, teorema de } \\
\text { Pitágoras, triângulos isósceles e } \\
\text { equilátero. }\end{array}$ \\
\hline $3 \underline{a}$ & $\begin{array}{l}\text { A transformação da } \\
\text { corda em seno }\end{array}$ & $\begin{array}{l}\text { Calcular o seno de um ângulo através } \\
\text { do valor da meia-corda. }\end{array}$ & $\begin{array}{l}\text { Triângulos, mediatriz de um } \\
\text { segmento e seno. }\end{array}$ \\
\hline $4 \underline{a}$ & $\begin{array}{l}\text { O radiano como unidade } \\
\text { de medida angular }\end{array}$ & $\begin{array}{l}\text { Conceituar o radiano como unidade de } \\
\text { medida e compará-lo com o grau. }\end{array}$ & $\begin{array}{l}\text { Circunferência, triângulos } \\
\text { isósceles e equilátero e } \\
\text { unidades de medidas de arcos. }\end{array}$ \\
\hline 5a & $\begin{array}{c}\text { O seno na circunferência } \\
\text { unitária }\end{array}$ & $\begin{array}{l}\text { Conceituar o seno na circunferência } \\
\text { trigonométrica e estabelecer } \\
\text { propriedades do seno através do seu } \\
\text { gráfico. }\end{array}$ & $\begin{array}{l}\text { Circunferência, projeções } \\
\text { ortogonais e seno. }\end{array}$ \\
\hline
\end{tabular}

$\mathrm{Na}$ elaboração da sequência, tivemos sempre em mente o caminho percorrido pelo conhecimento trigonométrico desde a Antiguidade. Ou seja, nossas atividades têm base na geometria euclidiana necessária à transição para a trigonometria moderna.

Para maiores informações sobre o caderno de atividades para o ensino de trigonometria numa abordagem histórica consultar Gomes (2011).

\section{CONSIDERAÇÕES FINAIS}

Diversos estudos no campo da Educação Matemática buscam formas diferenciadas de se 
trabalhar o conhecimento matemático em sala de aula. Estes estudos tratam de divulgar estratégias de ensino de Matemática através da modelagem, dos recursos tecnológicos, da resolução de problemas, da Etnomatemática, dos jogos e da História da Matemática.

Para que essas abordagens de ensino sejam viáveis, as instituições de formação de professores devem dar subsídios para que os docentes conheçam, dominem e possam utilizá-las em sala de aula com plena segurança.

Além disso, o compromisso do professor com sua formação deve ser competência profissional básica, pois "A formação contínua conserva certas competências relegadas ao abandono por causa das circunstâncias." (PERRENOUD, 2000, p.155). Ou seja, as práticas pedagógicas mudam, o conhecimento evolui e os recursos cognitivos, na figura do professor, devem acompanhar essa agilidade.

Assim, ao optarmos por elaborar uma sequência de ensino de trigonometria através da abordagem histórica, além de contribuir com a disseminação desta abordagem, estamos propondo aos leitores uma reflexão acerca da forma de como a História da Matemática é abordada (caso exista) nos cursos de formação e aperfeiçoamento de professores.

Após avaliação do curso mencionado, para que a utilização desse material (ou parte dele) seja viável em sala de aula, os professores interessados devem considerar alguns requisitos básicos: ter conhecimentos em geometria, domínio de cálculos algébricos e com números irracionais, familiaridade com construções geométricas e com o estudo das funções. Sem uma preparação prévia dos participantes com relação a esses conteúdos matemáticos mencionados, nossa proposta ficará bastante limitada.

Além disso, a utilização da sequência de atividades pode ser aliada ao uso de alguma ferramenta educacional informatizada. No nosso curso utilizamos o software GeoGebra para a construção de algumas figuras geométricas e gráfico de função seno. Esse recurso foi utilizado como auxiliar durante a resolução e discussão de algumas tarefas das atividades.

Caso não seja possível a utilização de algum software de geometria dinâmica, sugerimos a construção geométrica com régua e compasso para as atividades iniciais da sequência. Neste caso, o professor deverá buscar enriquecer as informações geométricas contidas na sequência com alguns estudos complementares para desenvolvimento cognitivo dos alunos.

\section{REFERÊNCIAS BIBLIOGRÁFICAS}

1. BARONI, R. L. S; NOBRE, S. A pesquisa em História da Matemática e suas relações com a Educação Matemática. In: BICUDO, M. A. V. (Org.). Pesquisa em Educação Matemática: concepções e perspectivas. São Paulo: UNESP, 1999. p. 129-136.

2. BRASIL, Ministério da Educação do. Orientações curriculares para o ensino médio. Brasília: Ministério da Educação, Secretaria de Educação Básica, 2006.

3. BRITO, A. de J.; MOREY, B. B. Geometria e Trigonometria: dificuldades de professores do ensino fundamental. In: FOSSA, John A. (org). Presenças matemáticas. Natal: EDUFRN, 2004. p. 9-33.

4. FASANELLI, F. The political context. In: FAUVEL, J.; MAANEN, J. V. (Eds.). History in mathematics education: the ICMY study. Dordrecht: Kluwer, 2002. 
5. FERREIRA, E. S. Laboratório de história da matemática. Natal: SBHMat. 2001.

6. FIORENTINI D.; LORENZATO S. Investigação de ensino de matemática: Percursos teóricos metodológicos. 2. ed. rev. Campinas: Autores Associados, 2007.

7. GOMES, S. C. Elaboração e aplicação de uma sequência de atividades para o ensino de trigonometria numa abordagem histórica. Dissertação (Mestrado em Ensino de Ciências e Matemática) - Universidade Federal do Rio Grande do Norte, Natal, 2011.

8. LIMA, E. L. (Ed.). Exame de Textos: Análise de Livros de Matemática para o Ensino Médio. In: Revista do professor de matemática. n. 46. Rio de Janeiro: SBM, 2001. p. 43-51.

9. MENDES, I. A. O uso da história no ensino da matemática: reflexões teóricas e experiências. Belém: UEPA, 2001a.

10. MENDES, I. A. Ensino de matemática por atividades: uma aliança entre o construtivismo e a história. Natal: UFRN, 2001b. Tese (Doutorado em Educação).

11. MENDES, M. J. F.; ROCHA, M. L. P. C. Problematizando os caminhos que levam à tabela trigonométrica. Belém: SBHMat, 2009.

12. MIGUEL, A.; MIORIM, M. A. História na Educação Matemática: propostas e desafios. 1. ed. Belo Horizonte: Autêntica, 2005.

13. MOREIRA, P. C.; DAVID, M. M. M. S. A formação matemática do professor: licenciatura e prática docente escolar. Belo Horizonte: Autêntica, 2007.

14. NACARATO, A. M.; BREDARIOL, C. C.; PASSOS, M. P. F. Tendências presentes no ensino de trigonometria no Brasil: uma abordagem histórica. In: MENDES, J. R.; GRANDO, R. C. (Org.). Múltiplos olhares: matemática e produção de conhecimento. São Paulo: Musa Editora, 2007. p. 65-93.

15. NASCIMENTO, A. Z. Uma sequência de ensino para a construção de uma tabela trigonométrica. São Paulo: PUC, 2005. Dissertação (Mestrado Profissional em Ensino de Matemática).

16. OSTERMANN, F.; REZENDE, F. Projetos de desenvolvimento e de pesquisa na área de ensino de ciências e matemática: uma reflexão sobre os mestrados profissionais. In. Cadernos Brasileiros de Ensino de Física, v. 25, n. 1. 2009. p. 66-80.

17. PERRENOUD, P. Dez novas competências para ensinar. Porto Alegre: ARTMED, 2000.

18. POLETTINI, A. F. F. Análise das experiências vividas determinando o desenvolvimento profissional do professor de matemática. In: BICUDO, M. A. V. (Org.). Pesquisa em Educação Matemática: concepções e perspectivas. São Paulo: UNESP, 1999. p. 247-261.

19. SAMPAIO, H. R. Uma abordagem histórico-filosófica na educação matemática: contribuições ao processo de aprendizagem em trigonometria no ensino médio. Londrina: UEL, 2008. Dissertação (Mestrado em Ensino de Ciências e Educação Matemática).

20. SIU, M. "No, I don't use history of mathematics in my class. Why?" In: Proceedings HPM 2004 \& ESU4. FURINGHETTI, F.; KAIJSER, S.; Tzanakis, C. (Eds.), Uppsala: Uppsala Universitet, 2004/2007. pp. 268-277.

21. ZABALA, A. A prática educativa: Como ensinar. Tradução Ernani F. da F. Rosa. Porto Alegre: Artmed, 1998. 